\title{
Efficiency of the SASS4 rapid bioassessment protocol in determining river health: A case study on the Mhlathuze River, KwaZulu-Natal, South Africa
}

\author{
P Vos ${ }^{1 *}$, V Wepener ${ }^{2}$ and DP Cyrus ${ }^{3}$ \\ 'Water Programme, Environmentek, CSIR, Pretoria, 0001, South Africa \\ ${ }^{2}$ Department of Zoology, Rand Afrikaans University, Johannesburg PO Box 524, Aucklandpark, 2006, South Africa \\ ${ }^{3}$ Coastal Research Unit of Zululand, University of Zululand, Private Bag X1001, KwaDlangezwa 3886, South Africa
}

\begin{abstract}
The purpose of the study was to verify the ability of the South African Scoring System version 4 (SASS4), to assess the health of aquatic ecosystems. The macroinvertebrate community attributes of the Mhlathuze River (KwaZulu-Natal, South Africa) were studied by applying the SASS4 rapid bioassessment method. In testing the effect of spatial and temporal variability in community structure on SASS4 scores it was found that there was a stronger spatial than a temporal effect. It was determined that of the indices used in association with SASS4, the biotic indices (average score per taxon, total score and number of taxa) reflected changes in community structure, but the abiotic habitat quality index did not. It was found that qualitative family-level data provided an adequate classification of sites for use in routine biomonitoring. Ambiguous results were obtained with respect to the importance of measuring abundance during routine biomonitoring. No definite conclusion with respect to the ability of the SASS4 to reflect physical-chemical water quality changes could be drawn from the results obtained in this study. SASS4 was able to reflect the effect of the tidal push from the Mhlathuze Estuary, but this marine influence probably masked less pronounced effects exerted by the remainder of the physical-chemical variables that were investigated.
\end{abstract}

\section{Introduction}

For the past few years, national attention has been focused on establishing a national biomonitoring programme for aquatic ecosystems. This has led to the establishment of the River Health Programme (RHP), as it is currently known. River or ecosystem health refers to the ability of ecosystems to function in a way comparable to that system in its natural state, and any reduction in this ability leads to a decrease in integrity (Roux et al., 1999). A healthy ecosystem would be able to:

- resist external pressures (resistance) and

- recover from unpreventable pressures (resilience) (Roux and Everett, 1994).

The SASS4 rapid bioassessment method forms an integral part of the RHP (Roux et al., 1999).

SASS4 was developed by Chutter (1994) as a quick, costeffective method for assessing river health (Dallas, 1997). The SASS4 protocol is essentially a biotic index of the condition of a river, based on the resident macroinvertebrate community, whereby each taxon is allocated a score according to its level of tolerance to river health degradation (Dallas, 1997). The advantage of SASS4 is that it has the potential for significantly reducing the labour and time factors confronting freshwater ecologists, since the number of habitats examined and the replicated sample units taken per site are reduced (Chutter, 1994). Dallas $(1995,1997)$ addressed some of the uncertainties associated with SASS4 and concluded that it has enormous potential as a rapid assessment tool for river health and that the widespread application of this method necessitates the founding of SASS4 on a sound scientific base.

Dallas (1997) identified some research needs aimed at addressing the founding of SASS4 on a sound scientific base. This paper attempts to address some of these needs through the formulation of

* To whom all correspondence should be addressed.

푱(012) 841-4146; fax. (011) 489-2286; e-mail: vos@csir.co.za Received 18 February 2000; accepted in revised form 2 November 2001. the following objectives, namely, to investigate:

- The effect of spatial and temporal variation on the accuracy of SASS4 in reflecting changes in macroinvertebrate community structure.

- The ability of the indices used in association with SASS4 to reflect changes in macroinvertebrate community structure.

- The effect of taxonomic resolution and quantification on the accuracy of SASS4 in representing macroinvertebrate community structure.

- The ability of SASS4 to reflect changes in physical-chemical water quality.

The SASS4 scores are affected by the availability and condition of habitat as well as changes in physical-chemical water quality. Thus, an integrative approach, which included physical-chemical, habitat and biological assessments, was followed to provide increased accuracy.

Limitations associated with the study included the scarcity of appropriate taxonomical keys and the fact that habitat indices existing at the time of sampling (HQI, HAM and HABS1) failed to provide an adequate estimation of habitat quality. MacMillan (1998) has since developed an alternative habitat index (IHAS) for use in conjunction with SASS4. Other limitations included the absence of site-specific data on certain important physical-chemical variables, such as flow and turbidity, the lack of truly quantitative data and the absence of separate datasets for each biotope.

\section{Materials and methods}

\section{Description of the Mhlathuze River catchment}

The Mhlathuze River is one of the larger rivers draining the Zululand Coastal Plain (Meyer and Godfrey, 1995). It originates in the foothills of the Babanango Mountain, approximately $1500 \mathrm{~m}$ a.s.l., $110 \mathrm{~km}$ north-west of Richards Bay. The total length of this perennial river is $208 \mathrm{~km}$ (Anonymous, 1983). The catchment, occupying an area of $4238 \mathrm{~km}^{2}$, has a storage capacity 


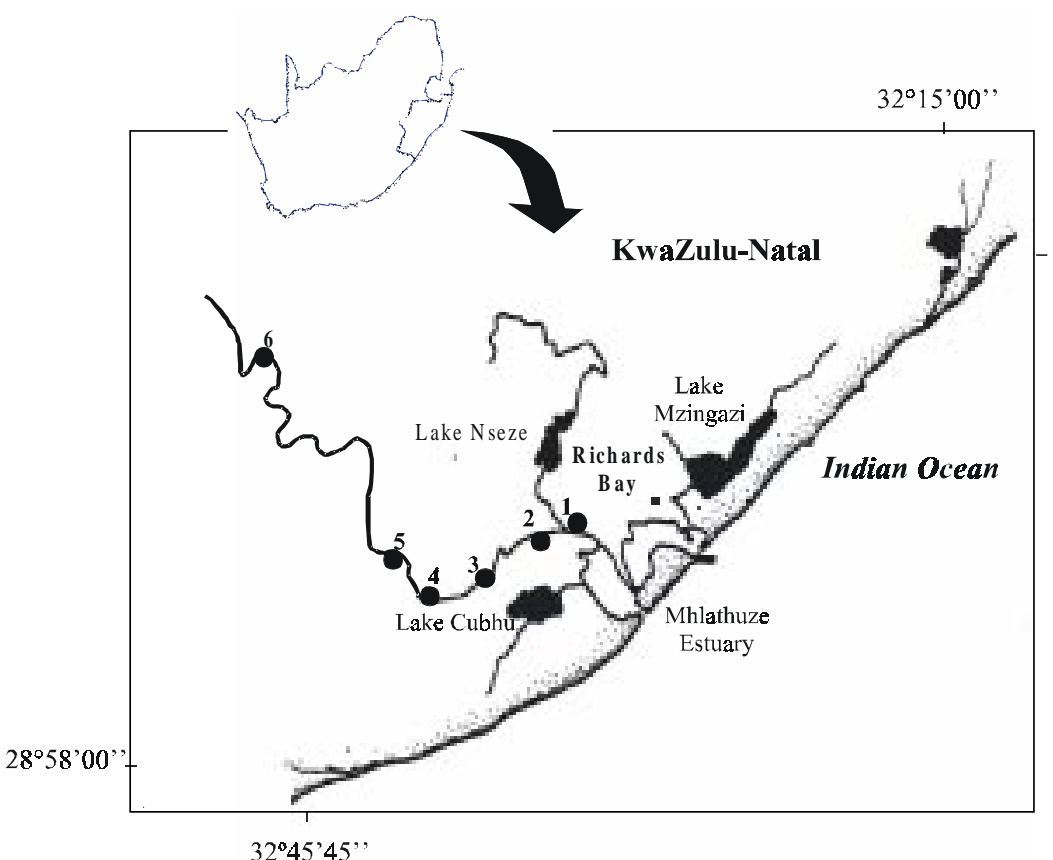

Figure 1

The Mhlathuze River study area showing the positions of the six sampling sites

potassium, sodium, calcium, ammonium and magnesium.

\section{Data analysis}

Non-parametric multivariate methods 28 $39^{\prime} 30^{\prime \prime}$ including hierarchical agglomerative clustering using group average linking (classification) and non-metric multidimensional scaling (ordination), were used to analyse the data. The BrayCurtis coefficient of similarity was applied to the presence-absencetransformed community data (based on SASS4 scores), while Euclidean distance was applied to the physicalchemical data as a dissimilarity coefficient. All data were analysed using the PRIMER version 4 (Clarke and Warwick, 1994).

Since the data used throughout the study is of a non-replicate nature, twoway analysis of similarity without replication was applied to the data in order to determine if results were statistically significant (Clarke and Warwick, 1994). The extent to which

of $5.2 \times 10^{6} \mathrm{~m}^{3}(1 \% \mathrm{MAR})$ in small dams, and an additional $304 \times 10^{6} \mathrm{~m}^{3}$ (53\% MAR) in the Goedertrouw Dam (Kelbe and Germishuyse, 1999).

The Mhlathuze River is characterised by unconsolidated mobile bed sediments, a steep gradient, high flow velocity, and a longitudinal profile consisting of a series of rapids with few large still pools. Bedrock is only found in the upper reaches of the river (Dollar, 1998). Water quality, which is dominated by sodium, chloride, and bicarbonate, is determined by geology in the upper reaches and by precipitation in the middle and lower reaches (Cyrus et al., 2000).

Catchment land use includes commercial wattle, pine and eucalyptus as well as sugar cane production (Dollar, 1998). The major sources of pollution carried by rivers and streams are domestic effluent, agricultural waste, and sewage, which lead to severe widespread nitrate contamination of water resources in the area (Meyer and Godfrey, 1995).

\section{Study site selection}

The lower section of the Mhlathuze River formed the study area (Fig. 1). Sites were selected above and below possible sources of impact. Site 1 was situated below the confluence of the Mhlathuze and Nseleni Rivers, Sites 2 and 3 were situated below and above the DWAF flow-gauging weir respectively. Sites 4 and 5 were situated below and above the village Felixton respectively to monitor the possible ecological effects of the Felixton sugar mill. Site 6 represented the uppermost site within the study area.

\section{Field protocol}

SASS4 and HQI assessments were conducted at six sites on the Mhlathuze River on a monthly basis from April 1996 to March 1997. Additionally, 19 water quality variables were measured at each site, including $\mathrm{pH}$, conductivity, percentage oxygen saturation, dissolved oxygen, temperature, total dissolved solids, silicon, total alkalinity, chloride, sulphate, fluoride, nitrate, nitrite, phosphorus, the observed community patterns reflected the sample patterns generated by the physical-chemical data was examined through a procedure that selects the physical-chemical variable combination (also referred to as the "maximum variable combination"), which is most likely responsible for structuring the macroinvertebrate community.

Since Site 1 was found to differ to such an extent from Sites 2 to 6 , those differences among these sites were masked. It was removed from the data set for the analyses, which investigated:

- the effect of spatial and temporal variation on the accuracy of SASS4 in reflecting changes in community structure; and

- the ability of SASS4 to reflect changes in physical-chemical water quality.

Separate analyses were conducted on the data from Site 1. Due to the limited number of sampling points available when analysing a single site, these analyses were done on an annual basis. The analyses on all sites (Sites 1 to 6) and on the subset of the sites (Sites 2 to 6) were conducted on a monthly basis, except in instances where more than two variables were compared, as was the case for the investigations into:

- the ability of indices used in association with SASS4 to reflect changes in macroinvertebrate community structure; and

- the effect of taxonomic resolution and quantification on the accuracy of SASS4 in representing macroinvertebrate community structure, where data were analysed seasonally.

\section{Results and discussion}

\section{Description of codes used}

The codes used throughout the results and discussion section are presented in Table 1. It is important to note that the individual index scores and water quality data values for each site are not reported in this paper. The reader is referred to Cyrus et al. (2000) for actual values. 
Effect of spatial and temporal variation on the accuracy of SASS4 in reflecting changes in macroinvertebrate community structure

In order to illustrate any temporal and/or spatial trends, present cluster and ordination analyses were conducted separately for each month across the six sampling sites on presence-absence-transformed family level data (hereafter referred to as community data) and SASS4 scores respectively.

Rejection of the null hypothesis of "no inter-site differences" would be suggested by a common site pattern in the separate ordination plots for the 12 times. In the same way, one can also test the hypothesis that there were no differences across times for the sampling sites. The significance of these spatial and temporal trends was tested by a two-way analysis of similarity (using the Spearman's rank correlation coefficient). Community data were analysed through classification and ordination analyses. Groups formed in the cluster analysis (at the rank similarity cut-offs presented in Table 2) were superimposed onto the ordinations in order to minimise the chances of misinterpretation. The results of the analyses, and reference to the associated plots, are presented in Table 4.

The significance of the observed spatial and temporal trends in SASS4 scores and community data was tested by a two-way analysis of similarity without replication (Table 3). The Spearman's rank correlation coefficients $(\rho)$ for all pairs of times were averaged to give $\rho_{\mathrm{av}}$, which takes values in the range $[-1,1]$, with values around zero corresponding to a lack of correlation.

Spatial and temporal variation in both community data and SASS4 scores were significant in all but one instance (Table 3: $\rho_{\text {av }}$ $=0.004$ ). A stronger spatial than temporal trend in both community data and SASS4 scores was observed throughout, except when Site 1 was excluded from the analysis. Excluding Site 1 from the analysis resulted in the temporal effect becoming more important than the spatial effect. This was probably due to the fact that the spatial difference established between Site 1 and the remaining sites, by a clearly evident marine effect, overshadowed any temporal differences.

The fact that a spatial trend was detected in the community data, but not in the SASS4 data might be explained as follows:

- SASS4 data is less sensitive than community data to inter-site differences in community structure due to possibly erroneous sensitivity ratings incorporated into the SASS4 scores.

- SASS4 score as an index is robust enough not to be affected by temporal changes in community structure.

The latter explanation is unlikely, since this phenomenon was only observed once, whereas biotic indices are reputedly affected by temporal variation.
TABLE 1

aper for graphical representation of results

\begin{tabular}{|c|c|c|c|c|c|c|c|}
\hline Sites & \multicolumn{7}{|c|}{ Mhlathuze River sites } \\
\hline $\begin{array}{l}\text { Site } 1 \\
\text { Site } 2 \\
\text { Site } 3 \\
\text { Site } 4 \\
\text { Site } 5 \\
\text { Site } 6\end{array}$ & \multicolumn{7}{|c|}{$\begin{array}{l}\text { Closest site to the Mhlathuze Estuary } \\
\text { Below the Nseleni-Mhlathuze confluence } \\
\text { Above the Nseleni-Mhlathuze confluence } \\
\text { Below the Felixton sugar mill } \\
\text { Above the Felixton sugar mill } \\
\text { Uppermost site }\end{array}$} \\
\hline \multicolumn{8}{|c|}{ Seasons (March 1996 - February 1997) } \\
\hline \multicolumn{2}{|c|}{ Autumn } & \multicolumn{2}{|c|}{ Winter } & \multicolumn{2}{|c|}{ Spring } & \multicolumn{2}{|c|}{ Summer } \\
\hline Code & Time & Code & IIme & Code & IIme & Code & \\
\hline $\begin{array}{l}\text { (l) } \\
\text { (a) } \\
\text { (b) }\end{array}$ & $\begin{array}{l}\text { Mar } \\
\text { Apr } \\
\text { May }\end{array}$ & $\begin{array}{l}\text { (c) } \\
\text { (d) } \\
\text { (e) }\end{array}$ & $\begin{array}{c}\text { Jun } \\
\text { Jul } \\
\text { Aug }\end{array}$ & $\begin{array}{l}\text { (f) } \\
\text { (g) } \\
\text { (h) }\end{array}$ & $\begin{array}{l}\text { Sep } \\
\text { Oct } \\
\text { Nov }\end{array}$ & $\begin{array}{l}\text { (i) } \\
\text { (j) } \\
(\mathrm{k})\end{array}$ & $\begin{array}{l}\text { Dec } \\
\text { Jan } \\
\text { Feb }\end{array}$ \\
\hline \multicolumn{8}{|c|}{ Index codes } \\
\hline Code & \multicolumn{7}{|c|}{ Description } \\
\hline $\begin{array}{l}\text { SASS4 } \\
\text { NTAXA } \\
\text { ASPT } \\
\text { HQI }\end{array}$ & $\begin{array}{l}\text { Total s } \\
\text { Numbe } \\
\text { Averas } \\
\text { Habita }\end{array}$ & $\begin{array}{l}\text { f taxa } \\
\text { core pe } \\
\text { ality in }\end{array}$ & & & & & \\
\hline
\end{tabular}

TABLE 2

Spatial and temporal trends in community structure and SASS4 scores detected through classification and ordination analyses

\begin{tabular}{|l|l|c|l|}
\hline Sites & RSC & Figure & Comment \\
\hline All & 10 & 2 & $\begin{array}{l}\text { Site 1 remained separated from } \\
\text { the rest of the sites through time, } \\
\text { however the pattern amongst } \\
\text { the remaining five sites did not } \\
\text { remain constant. }\end{array}$ \\
\hline 1 & 30 & 3 & $\begin{array}{l}\text { No definite temporal trend was } \\
\text { obvious from the ordination. }\end{array}$ \\
\hline $2-6$ & 4 & 4 & $\begin{array}{l}\text { Some definite spatial and temporal } \\
\text { trends were observed. }\end{array}$ \\
\hline
\end{tabular}

- For Fig. 3 the alpha numerals relevant to the specific analyses are indicated in brackets

- $\mathrm{RSC}=$ rank similarity cut-off

\section{Ability of SASS4, ASPT, NTAXA and HQI to reflect changes in macroinvertebrate community structure}

The relationship between community structure and SASS4, ASPT, NTAXA and HQI, was investigated by superimposing these index values separately onto the ordination resulting from the community data. Similar magnitudes of index values within groups proved the ability of indices to reflect changes in community structure. Cluster 


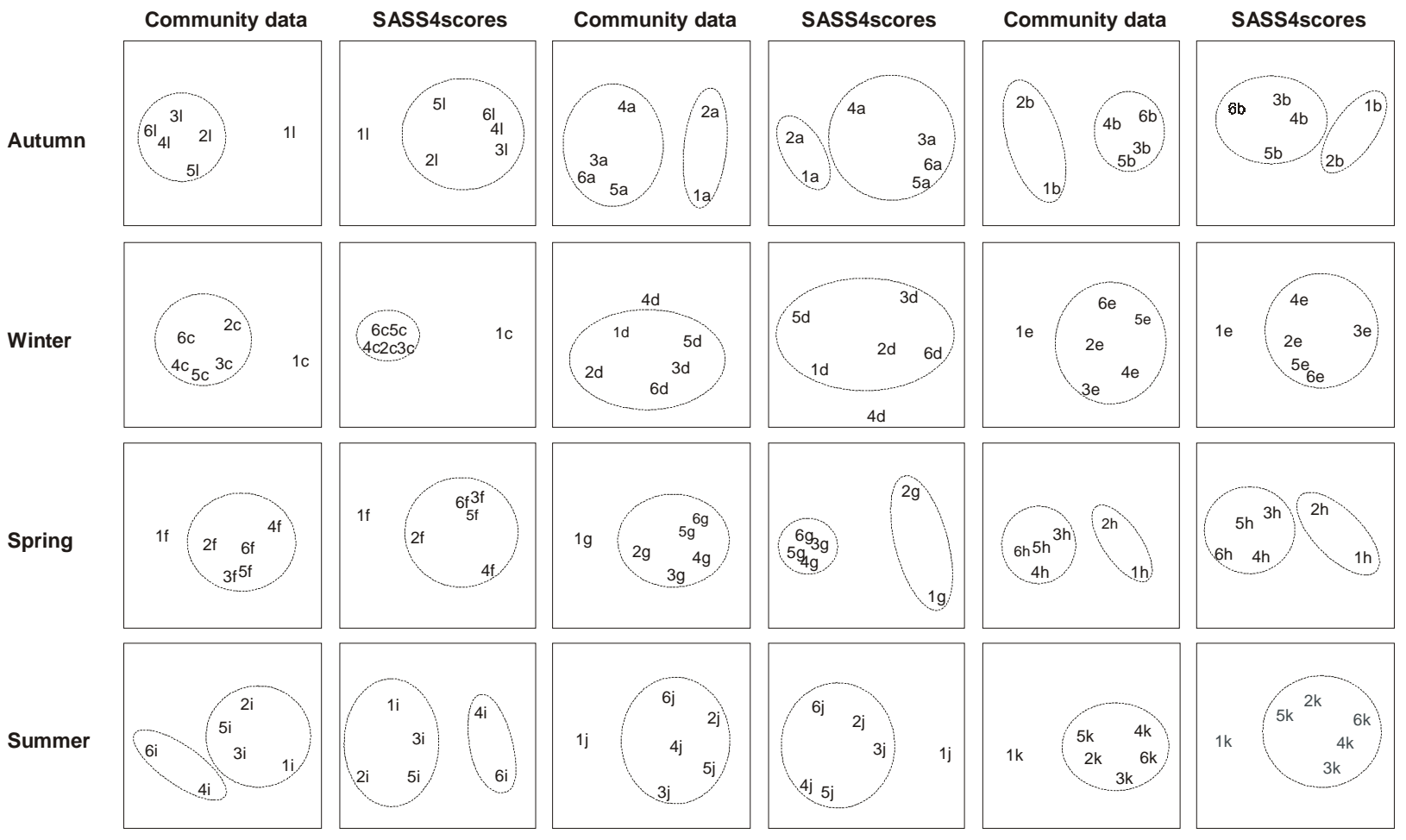

Figure 2

Monthly ordinations generated from presence-absence-transformed family level data and SASS4 scores respectively, collected at all six sites for the duration of the study. Superimposed cluster groups were formed at a rank similarity cut-off of 10.
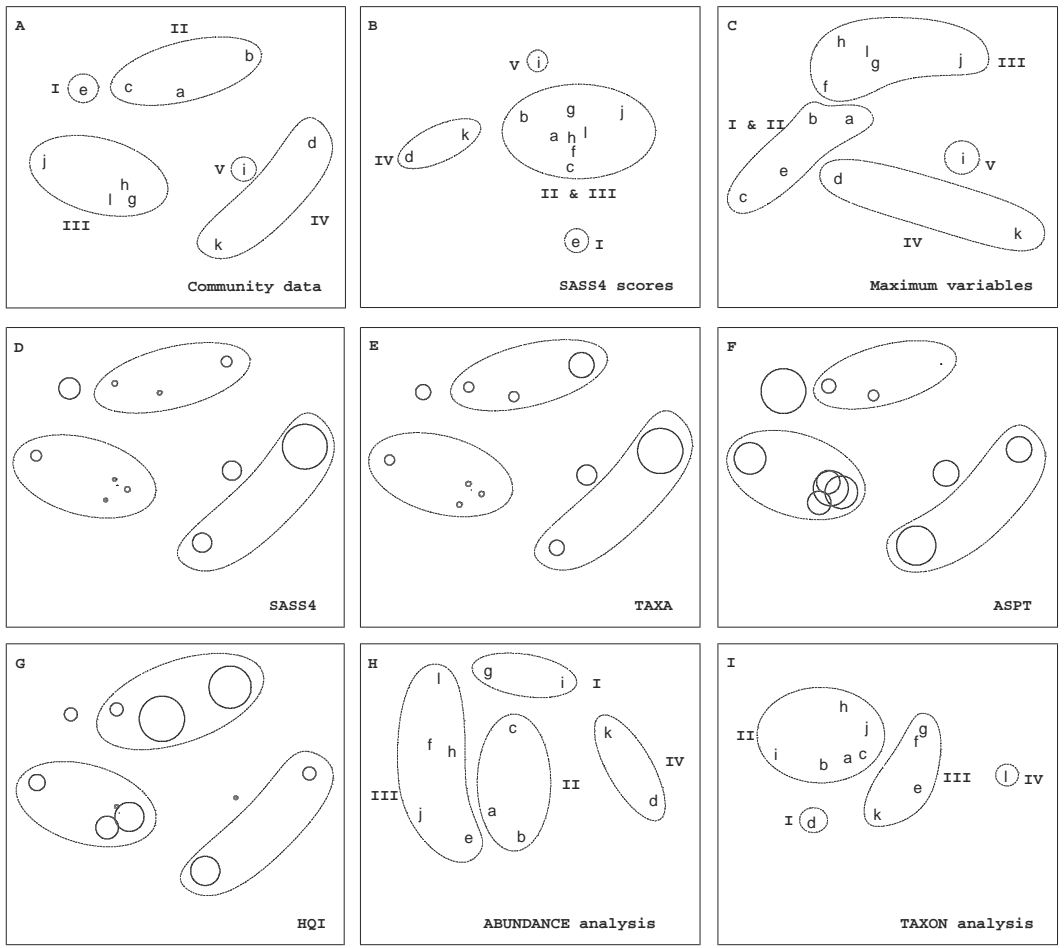

Figure 3

Annual ordinations of all analyses, generated from data collected at Site 1 for the duration of the study.

Superimposed cluster groups were formed at a rank similarity cut-off of 30 The following codes apply: $A$ Presence-absence-transformed family level data, $B$ - Total scores, C - Logtransformed maximum variable combination, $D$ - Superimposed SASS4 values, $E$ - Superimposed NTAXA values, $F$ - Superimposed ASPT values, $G$ - Superimposed $H Q I$ values, $H$ Semi-quantitative data based on relative abundances of SASS4 families,

I - Qualitative data at a higher taxonomic resolution than SASS4 families groups formed at a rank similarity cut-off of 30 were added manually to the ordinations in order to minimise the probability of misinterpretation.

Table 4 presents the amount of within group variability detected for each index as well as the number (and code) of samples responsible for most of the variability within these groups. General comments are provided with respect to the similarity of sample patterns among the different indices.

Although there were some discrepancies between the patterns generated by the three biotic indices (SASS4, ASPT and NTAXA) and those generated by the community data, they generally succeeded in satisfactorily reflecting sample groupings (Table 4). This gives 


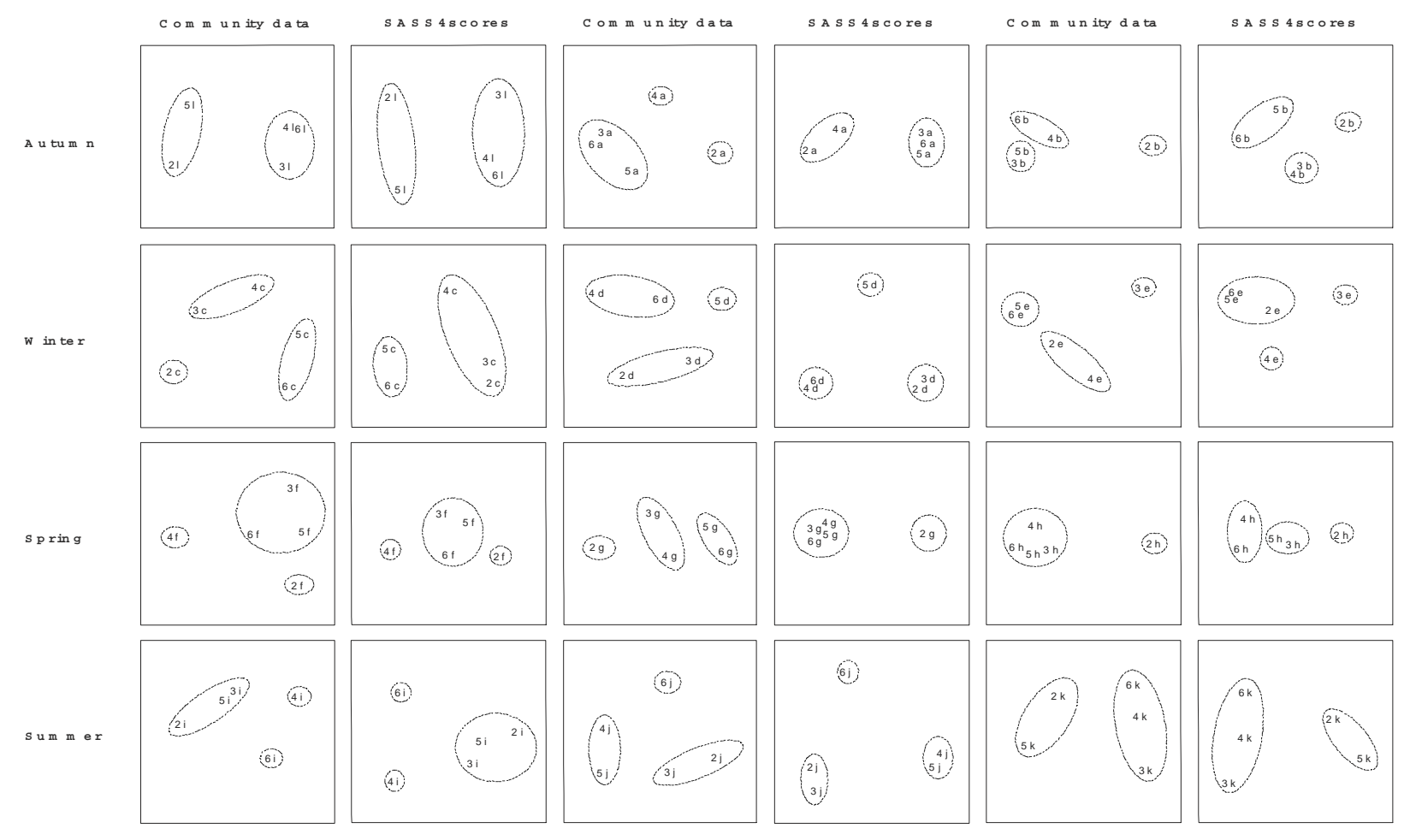

Figure 4

Monthly ordinations generated from presence/absence-transformed family level data and SASS4 scores respectively, collected at sites 2 to 6 for the duration of the study. Superimposed cluster groups were formed at a Rank Similarity Cut-off of 4.

an indication of the ability of SASS4, NTAXA and ASPT to distinguish macroinvertebrate community patterns at the study sites.

There was, however, a general lack of correlation between the abiotic index, HQI, and the three biotic indices (Table 4), which indicated either that:

- HQI was not sensitive enough to detect the habitat changes, which affected the macroinvertebrate community or

- habitat quality did not play an important role in structuring the macroinvertebrate community inhabiting the Mhlathuze River.

Although it has been reported by some authors (e.g. Growns et al., 1995) that most biotic indices cannot be used as a valid measure of water quality, the above-mentioned results, refute such findings.

\section{Effect of taxonomic resolution and quantification on the accuracy of SASS4 in representing macro- invertebrate community structure}

The ability of the SASS4 rapid assessment protocol to reveal the same community patterns as those revealed by data at a higher level of taxonomic resolution and quantification, were tested by comparing community patterns obtained through the classification and ordination of community data at three different levels of detail (Table 5). Cluster groups formed at a rank similarity cut-off of 30 were added manually to the ordinations in order to minimise the probability of misinterpretation.

Table 6 presents the disagreement in and among sample relationships observed between groups formed in the FAMILY analysis and the ABUNDANCE and TAXON analyses respectively.

The match between the community matrix (generated by the FAMILY analysis) and each of the other two data matrices (generated by the TAXON and ABUNDANCE analyses respectively) was

\begin{tabular}{|c|c|c|c|c|}
\hline \multicolumn{5}{|c|}{$\begin{array}{c}\text { TABLE } 3 \\
\text { Significance of the spatial and temporal trends in } \\
\text { SASS4 scores and community data presented as } \\
\text { Spearman's rank correlation coefficients }(\rho) \text {. } \\
\text { Asterisks indicate } p \leq 0.05 \text {. }\end{array}$} \\
\hline \multirow[t]{2}{*}{ Sites } & \multicolumn{2}{|c|}{ Temporal variation $\left(\rho_{\mathrm{av}}\right)$} & \multicolumn{2}{|c|}{ Spatial variation $\left(\rho_{\mathrm{av}}\right)$} \\
\hline & SASS4 & Community & SASS4 & Community \\
\hline All & 0.170 & 0.201 & 0.338 & 0.376 \\
\hline 1 & - & - & - & - \\
\hline $2-6$ & 0.241 & 0.278 & $0.004 *$ & 0.102 \\
\hline
\end{tabular}

computed through an analysis of similarity. No significant differences were found between similarity matrix patterns generated by the three different analyses.

The multivariate analysis compared the effect of the different levels of taxonomic resolution and quantification on the classification of sites. It was found that qualitative family level data provided an adequate classification for use in routine biomonitoring (Table 6). Similar results have been obtained by many, including Furse et al. (1981), Armitage et al. (1983), Castella et al. (1995), Dallas (1995) and Zamora-Munoz and Alba-Tercedor (1996), indicating that, despite the opinion of some authors (Growns et al., 1995), the necessary information about water quality can be provided by qualitative family level data.

Although the abundance of data reported here was not obtained through the traditional method of quantitative box sampling, one would have expected a greater difference between the results obtained from the FAMILY and ABUNDANCE analyses if 
TABLE 4

Relationship between community structure and SASS4 [S], NTAXA [N], ASPT [A] and HQI [H]. The success of each index in reflecting community structure was determined by calculating the percentage of samples able to reflect changes in community structure $([\wp / \mathfrak{I}] \%)$.

\begin{tabular}{|c|c|c|c|c|c|c|c|c|c|c|}
\hline \multirow[t]{2}{*}{$\begin{array}{l}\text { Site } \\
\text { [Fig.] }\end{array}$} & \multirow[t]{2}{*}{ Time } & \multicolumn{4}{|c|}{$\begin{array}{l}\text { Samples producing within } \\
\text { group variability }(\wp)\end{array}$} & \multicolumn{4}{|c|}{$\begin{array}{l}\% \text { Success }(\wp / \mathfrak{I}) \text { in } \\
\text { reflecting community } \\
\text { structure }\end{array}$} & \multirow[t]{2}{*}{ Comment } \\
\hline & & $\mathbf{S}$ & $\mathbf{N}$ & A & $\mathbf{H}$ & S & $\mathbf{N}$ & A & $\mathbf{H}$ & \\
\hline $\begin{array}{c}1 \\
{[\text { Fig. 3] }}\end{array}$ & $\mathrm{Y}$ & $1 \mathrm{~b}, 1 \mathrm{~d}, 1 \mathrm{~h}$ & $1 \mathrm{~b}, 1 \mathrm{~d}, 1 \mathrm{~h}$ & $1 \mathrm{~b}, 1 \mathrm{~d}, 1 \mathrm{~h}$ & - & 75 & 75 & 75 & $\mathrm{U}$ & $\begin{array}{l}\text { SASS4 (D), NTAXA (E) and ASPT (F) } \\
\text { generated analogous sample patterns, which } \\
\text { were not comparable to those generated by } \\
\text { HQI (G). }\end{array}$ \\
\hline \multirow[t]{4}{*}{$\begin{array}{c}2-6 \\
{[\text { Fig. 5] }}\end{array}$} & A & $21,4 b, 6 b$ & $21,4 b, 6 b$ & $2 \mathrm{l}, 4 \mathrm{~b}, 6 \mathrm{~b}$ & - & 80 & 80 & 80 & $\mathrm{U}$ & $\begin{array}{l}\text { SASS4, NTAXA and ASPT generated } \\
\text { analogous sample patterns, which were not } \\
\text { comparable to those generated by HQI. }\end{array}$ \\
\hline & $\mathrm{W}$ & $6 c, 6 d$ & $6 c, 6 d$ & $6 c, 6 d$ & - & 87 & 87 & 87 & $\mathrm{U}$ & $\begin{array}{l}\text { SASS4, NTAXA, ASPT and, to a lesser extent, } \\
\text { HQI generated analogous sample patterns. }\end{array}$ \\
\hline & SP & $\begin{array}{l}3 \mathrm{f}, 5 \mathrm{~h} \\
5 \mathrm{~g}, 6 \mathrm{~h}\end{array}$ & $\begin{array}{l}3 \mathrm{f}, 5 \mathrm{~h} \\
5 \mathrm{~g}, 6 \mathrm{~h}\end{array}$ & $3 \mathrm{f}, 6 \mathrm{~h}$ & - & 73 & 73 & 87 & $\mathrm{U}$ & $\begin{array}{l}\text { SASS4 and NTAXA generated analogous } \\
\text { sample patterns that were more similar to } \\
\text { each other than to that generated by the ASPT. } \\
\text { There was no clear relationship between HQI } \\
\text { and the three biotic indices. }\end{array}$ \\
\hline & SU & $6 \mathrm{k}$ & $6 \mathrm{k}$ & $6 \mathrm{k}$ & - & 93 & 93 & 93 & $\mathrm{U}$ & $\begin{array}{l}\text { SASS4, NTAXA and ASPT generated } \\
\text { analogous sample patterns, which were not } \\
\text { comparable to those generated by HQI. }\end{array}$ \\
\hline \multicolumn{6}{|c|}{ Average $\%$ success } & 82 & 82 & 84 & $\mathrm{U}$ & $\begin{array}{l}\text { SASS4, ASPT and NTAXA generally } \\
\text { succeeded in reflecting community structure, } \\
\text { while HQI was generally unsuccessful. }\end{array}$ \\
\hline - $\mathrm{Fo}$ & Fig. 3 & $\begin{array}{l}\text { lipha } n \\
\text { ul; } \mathfrak{I}=\end{array}$ & $\begin{array}{l}\text { als re } \\
\text { al nun }\end{array}$ & $\begin{array}{l}t \text { to th } \\
\text { of sam }\end{array}$ & & & & & & $\begin{array}{l}\text { s after each variable } \\
\text { er of samples producing within group }\end{array}$ \\
\hline
\end{tabular}

abundance had been very important in assessing the macroinvertebrate community structure. From the results obtained during this study it can not be said with absolute certainty that abundance was unimportant. This aspect was tested in more detail by Dallas (1995), who concluded that the qualitative rapid bioassessment method, SASS4, was able to distinguish the same site differences as were revealed by intensive quantitative benthic sampling.

According to Furse et al. (1981) the cost of the gain in information conferred by using detailed taxonomic data is probably unjustifiable. Conducting a detailed taxonomic analysis is immensely time-consuming and requires a great deal of expertise. Furthermore, the attainable level of the taxonomic resolution of the various groups is not comparable.

Macroinvertebrates often have contiguous distributions in rivers and streams, leading to greatly variable numbers between samples. It has been found that, in general, indices, which relied on abundance data, are inferior to those using binary (presence-absence) data (Thorne and Williams, 1997). It has also been found that some patterns in macroinvertebrate community structure may be obscured at species-level resolution (Furse et al., 1981).

\begin{tabular}{|l|l|l|}
\hline \multicolumn{3}{|c|}{$\begin{array}{c}\text { TABLE 5 } \\
\text { Description of codes and analyses used in this } \\
\text { section }\end{array}$} \\
\hline $\begin{array}{l}\text { Type of } \\
\text { analysis }\end{array}$ & $\begin{array}{l}\text { Level of taxonomic } \\
\text { resolution }\end{array}$ & $\begin{array}{l}\text { Level of } \\
\text { quantification }\end{array}$ \\
\hline $\begin{array}{l}\text { FAMILY } \\
\text { TAXON }\end{array}$ & $\begin{array}{l}\text { SASS4 families } \\
\text { Highest taxonomic } \\
\text { resolution possible }\end{array}$ & $\begin{array}{l}\text { Qualitative } \\
\text { Qualitative }\end{array}$ \\
ABUNDANCE & SASS4 families & Semi-quantitative \\
\hline
\end{tabular}

\section{Ability of SASS4 to reflect changes in physical- chemical water quality}

Classifications and ordinations were generated to illustrate the match between the patterns generated by the community (biotic) data and those generated by physical-chemical (abiotic) data. Variables were transformed to reduce skewness to an acceptable 

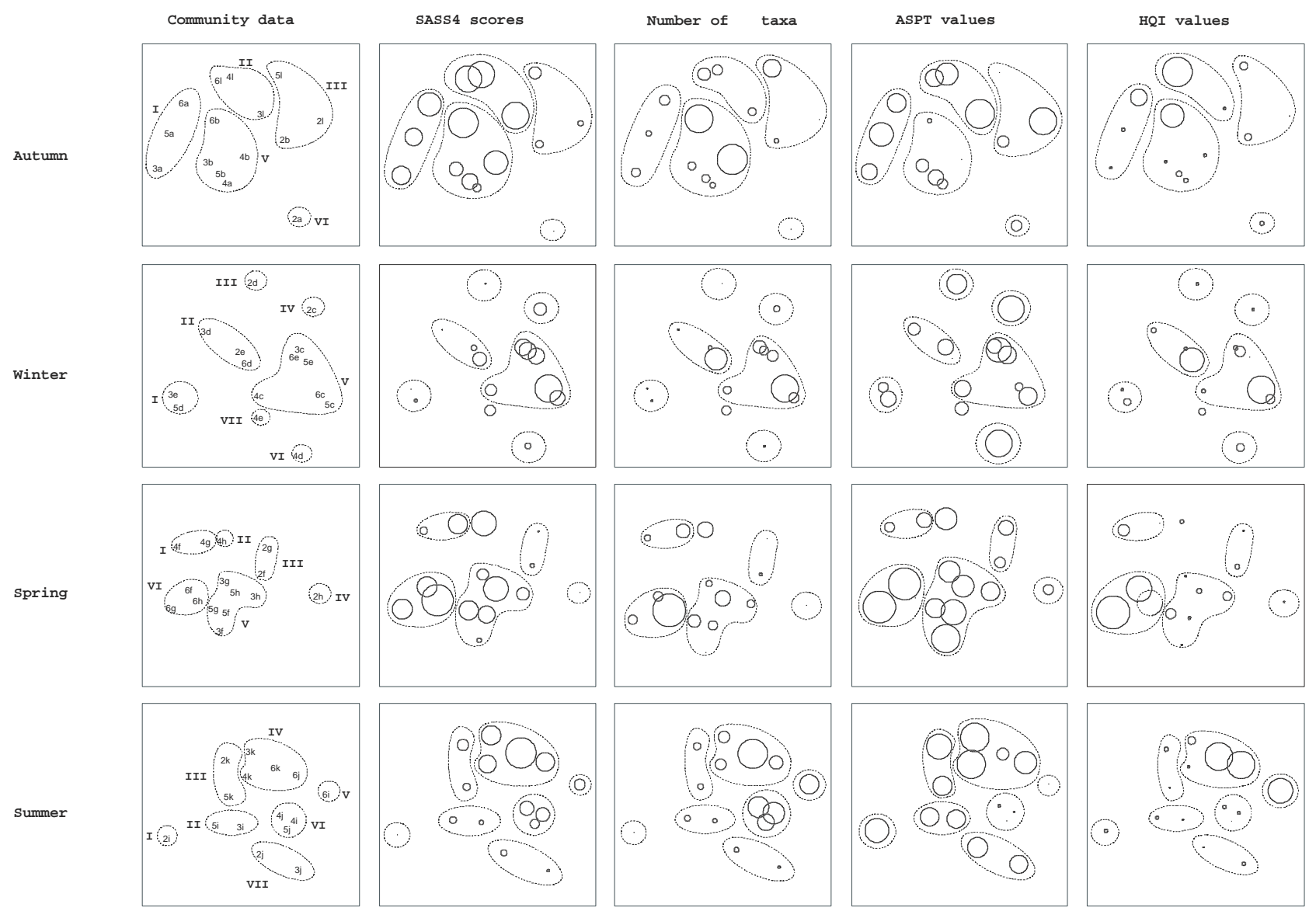

Figure 5 (above)

Seasonal ordinations generated from data collected at Sites 2 to 6 for the duration of the study. SASS4, NTAXA, ASPT and HQI values

were superimposed onto the MDS configurations of presence-absencetransformed family level data.

Figure 6 (right)

Seasonal ordinations of community data at three different levels of detail, collected at Sites 2 to 6 for the duration of the study.

Superimposed cluster groups were formed at a rank similarity cut-off of 30 , unless otherwise stated in Table 6.

level (skewness values between -3 and 3 ), and cluster groups were superimposed onto the ordinations to minimise chances of misinterpretation.

The variable subset chosen to represent the full set of physical-chemical data consists of those water quality variables that have known effects on biota (hereafter referred to as "variables of concern"). It is scientifically sound to perform the analysis on variables which are directly implicated (based on current toxicological knowledge) in biological effects, since this would ensure the best possible match between the biotic and abiotic data matrices. The physical-chemical dataset was divided into "variables of concern" and "correlated variables" that represent variables that are related to "variables of concern" (Table a) FAMILY analyses

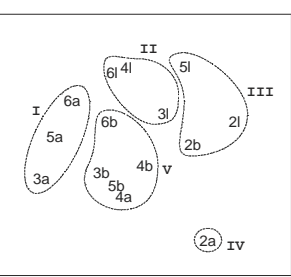

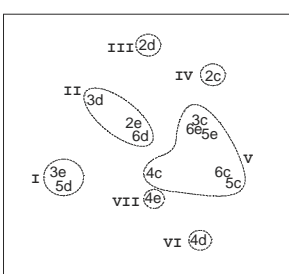
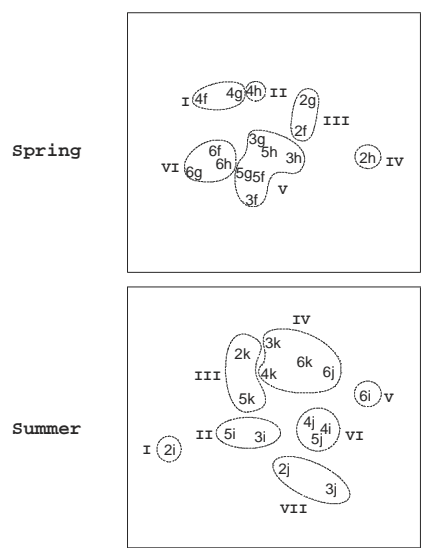

b) ABUNDANCE analyses
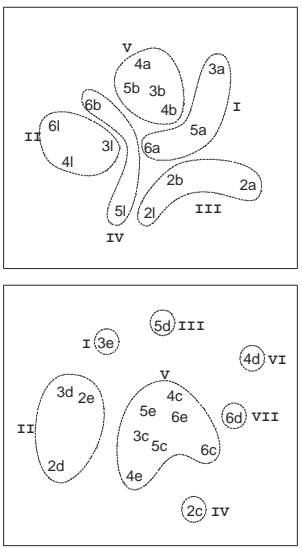

c) TAXON analyses
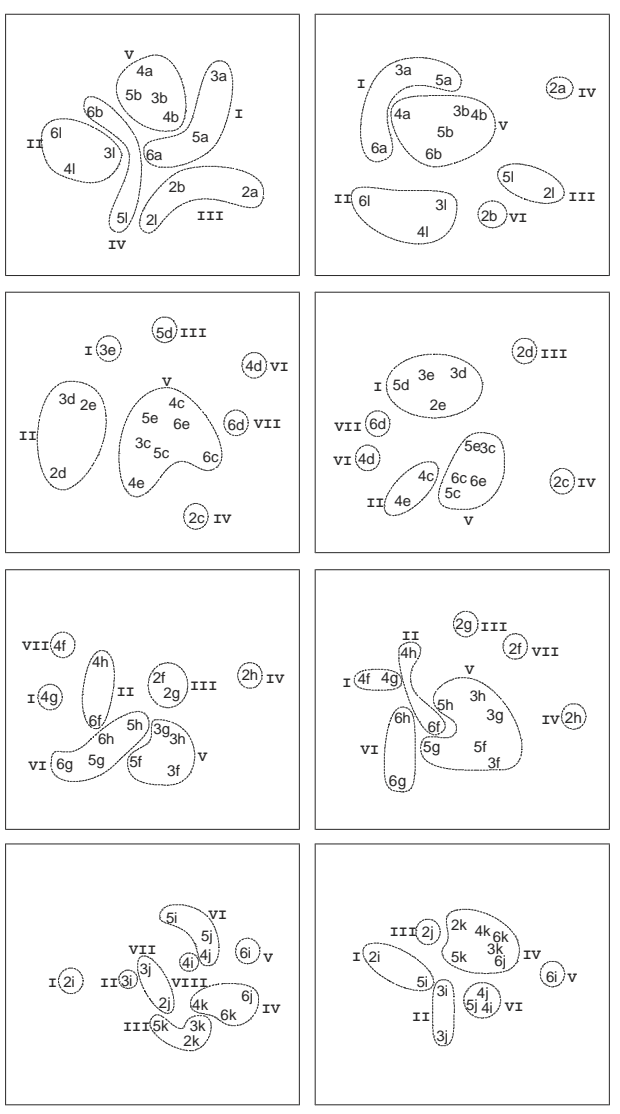
Table 8 presents "variables of concern" chosen to represent the physical-chemical dataset, the abiotic variable combination that best grouped sites in a manner consistent with macroinvertebrate community patterns (hereafter referred to as the "maximum variable combination"), and the weighted Spearman's rank correlation coefficient $\left(\rho_{\omega}\right)$ calculated between the ranks of the biotic and abiotic similarity matrices.

The weighted Spearman's rank correlation coefficient $\left(\rho_{\omega}\right)$ does not measure significance, but gives an indication of the degree of matching between the abiotic and biotic sample patterns. The "maximum variable combination" suggests a combination of abiotic variables most likely to be important in structuring the macroinvertebrate community, as opposed to providing a set of abiotic variables with a statistically significant effect on biotic patterns.

Agreement between sample patterns generated by the full set of abiotic variables and the macroinvertebrate community respectively, was measured by calculating the Spearman's rank correlation coefficient $(\rho)$ between the rank similarities of the abiotic and biotic matrices (Table 9).

When observing the Mhlathuze River system as a whole (all sites), there was agreement between the abiotic and biotic sample patterns. When the sites were analysed separately, however, this relationship degenerated (Table 9). The relationship between the abiotic and biotic patterns in the Mhlathuze River was based chiefly on the effect of the tidal push from the Mhlathuze Estuary, which resulted in a complete shift in community structure (i.e. it became dominated by estuarine species) during low-flow periods as a result of insufficient dilution of the saltwater intrusion from the estuary (Cyrus et al., 2000). This marine influence probably masked differentiation between the remaining sites (Sites 2 to 6).

The lack of agreement between the patterns generated by the abiotic and biotic data, can possibly be explained by one or all of the following:

- It is possible that the "maximum variable combination" did not constitute a main driving force in the macroinvertebrate community structure, owing to the fact that only selected abiotic variables were analysed, and might, therefore, not be able to provide the best possible match.

- The Mhlathuze River constitutes a relatively impacted system and would not be expected to harbour sensitive species which are able to reflect slight changes in water quality.

- Indices which summarise data on macroinvertebrate community structure (e.g. ASPT and SASS4) often do not reflect the each variable
TABLE 6

Comparison between the FAMILY [F] analysis and the TAXON [T] and ABUNDANCE [A] analyses respectively, across all sites

\begin{tabular}{|c|c|c|c|c|}
\hline \multirow[t]{2}{*}{$\begin{array}{l}\text { Site } \\
\text { [Fig.] }\end{array}$} & \multirow[t]{2}{*}{$\begin{array}{l}\text { Time } \\
\text { period }\end{array}$} & \multicolumn{2}{|c|}{$\begin{array}{l}\text { Samples producing } \\
\text { within group } \\
\text { variability }\end{array}$} & \multirow[t]{2}{*}{ Differences in sample associations } \\
\hline & & $F \& A$ & $F \& T$ & \\
\hline $\begin{array}{c}1 \\
{[\text { Fig.3] }}\end{array}$ & $\mathrm{Y}$ & $1 \mathrm{e}, 1 \mathrm{~g}$ & $\begin{array}{r}1 \mathrm{a}, 1 \mathrm{~b}, 1 \mathrm{c}, \\
1 \mathrm{e}, 1 \mathrm{k}, 1 \mathrm{l}\end{array}$ & $\begin{array}{l}\text { Five groups were formed in the FAMILY (A) } \\
\text { configuration and four in the ABUNDANCE } \\
\text { (H) and TAXON (I) plots. Disagreement in } \\
\text { among-sample relationships was more distinct } \\
\text { than those encountered when Sites } 2 \text { to } 6 \text { were } \\
\text { investigated. }\end{array}$ \\
\hline \multirow[t]{4}{*}{$\begin{array}{c}2-6 \\
{[\text { Fig.6] }}\end{array}$} & A & $2 a, 51,6 b$ & $2 b$ & $\begin{array}{l}\text { Five groups were formed in the FAMILY and } \\
\text { ABUNDANCE configurations, and seven in the } \\
\text { TAXON configuration. Disagreement in among- } \\
\text { sample relationships was observed between both } \\
\text { F \& A and F \& T. }\end{array}$ \\
\hline & $\mathrm{W}$ & $2 \mathrm{~d}, 4 \mathrm{e}, 6 \mathrm{~d}$ & $4 \mathrm{c}, 4 \mathrm{e}, 6 \mathrm{~d}$ & $\begin{array}{l}\text { Seven groups were formed in all three } \\
\text { configurations. Disagreement in among-sample } \\
\text { relationships was observed between both F \& A } \\
\text { and F \& T. }\end{array}$ \\
\hline & SP & $\begin{array}{l}4 \mathrm{~h}, 5 \mathrm{~g}, \\
5 \mathrm{~h}, 6 \mathrm{f}\end{array}$ & $4 h, 6 f$ & $\begin{array}{l}\text { Six sample groups were formed in the FAMILY } \\
\text { configuration, and seven in the ABUNDANCE } \\
\text { and TAXON plots. Disagreement in among- } \\
\text { sample relationships was observed between both } \\
\text { F \& A and F \& T. }\end{array}$ \\
\hline & SU & None & $\begin{array}{l}2 \mathrm{i}, 2 \mathrm{j}, 3 \mathrm{i} \\
3 \mathrm{j}, 5 \mathrm{i}\end{array}$ & $\begin{array}{l}\text { Six, seven and eight groups were respectively } \\
\text { apparent in the FAMILY, TAXON and } \\
\text { ABUNDANCE configurations. Altering the } \\
\text { rank similarity cut-off to } 40 \text { increased the } \\
\text { concordance between sample patterns. }\end{array}$ \\
\hline
\end{tabular}

For Fig. 3 alpha numerals relevant to the specific analyses are indicated in brackets after

TABLE 7

Division of the full physical-chemical dataset into "variables of concern" and "correlated variables"

\begin{tabular}{|l|l|}
\hline $\begin{array}{l}\text { "Variables of } \\
\text { concern" }\end{array}$ & "Correlated variables" \\
\hline $\begin{array}{l}\text { Ortho-phosphate } \\
\text { Ammonium } \\
\text { Temperature } \\
\text { pH }\end{array}$ & $\begin{array}{l}\text { Total phosphate } \\
\text { Nitrite and nitrate }\end{array}$ \\
$\begin{array}{l}\text { Fluoride } \\
\text { Dissolved oxygen }\end{array}$ & $\begin{array}{l}\text { Total alkalinity } \\
\text { Percentage oxygen saturation, chemical } \\
\text { oxygen demand } \\
\text { Total dissolved solids, sulphate, chloride, } \\
\text { calcium, magnesium, sodium, potassium }\end{array}$ \\
\hline
\end{tabular}




\begin{tabular}{|c|c|c|c|c|c|c|c|}
\hline \multicolumn{8}{|c|}{$\begin{array}{l}\text { TABLE } 8 \\
\text { The degree of matching between the "variables of concern" and the community structure across all sites for the } \\
\text { duration of the study, measured in terms of the weighted Spearman's rank correlation coefficient }\left(\rho_{\omega}\right) \text {. }\end{array}$} \\
\hline $\begin{array}{l}\text { Sites } \\
\text { [Fig.] }\end{array}$ & Time & $\begin{array}{l}\text { Trans- } \\
\text { form }\end{array}$ & RSC & Voc & MVC & $\rho_{\omega}$ & Comment \\
\hline $\begin{array}{c}\text { All } \\
\text { [Fig.7] }\end{array}$ & M & $\log _{10}$ & 10 & $\begin{array}{l}\text { Cond, } \mathrm{pH}, \mathrm{PO}_{4} \\
\mathrm{NH}_{4}, \mathrm{DO}, \mathrm{T}\end{array}$ & $\begin{array}{c}\text { Cond, } \mathrm{PO}_{4}, \\
\text { DO }\end{array}$ & 0.090 & $\begin{array}{l}\text { Although very similar sample patterns emerged } \\
\text { for the abiotic and biotic data for Site } 1 \text { and } 2 \text {, this } \\
\text { was not the case for the remaining four sites. In } \\
\text { order to determine, which combination of abiotic } \\
\text { variables best reflected the faunal pattern (i.e. to } \\
\text { ensure the best possible match) at all sampling sites, } \\
\text { it was necessary to separate Site } 1 \text { from the rest of } \\
\text { the sites for further analyses. }\end{array}$ \\
\hline $\begin{array}{c}1 \\
\text { [Fig.3] }\end{array}$ & Y & $\log _{10}$ & 30 & $\begin{array}{l}\text { Cond, } \mathrm{pH}, \\
\mathrm{NO}_{x}, \mathrm{PO}_{4}, \\
\mathrm{NH}_{4}, \mathrm{DO}, \mathrm{T}\end{array}$ & $\mathrm{NO}_{x}, \mathrm{PO}_{4}$ & 0.278 & $\begin{array}{l}\text { A low degree of concordance was observed } \\
\left(\text { see } \rho_{\omega}\right) \text { when comparing the sample patterns } \\
\text { generated by the abiotic (C) and biotic (A) data, } \\
\text { collected at Site } 1 .\end{array}$ \\
\hline $\begin{array}{c}2-6 \\
\text { [Fig. } 8]\end{array}$ & M & $\begin{array}{l}\text { Square- } \\
\text { root }\end{array}$ & 4 & $\begin{array}{l}\text { Cond, } \mathrm{pH}, \mathrm{PO}_{4}, \\
\mathrm{NH}_{4}, \mathrm{DO}, \mathrm{T}\end{array}$ & Cond, $\mathrm{pH}, \mathrm{PO}_{4}$ & 0.051 & $\begin{array}{l}\text { There was a general disagreement between the } \\
\text { sample patterns }\left(\text { see } \rho_{\omega}\right) \text { generated by the biotic and } \\
\text { abiotic data throughout the study period. }\end{array}$ \\
\hline \multicolumn{8}{|c|}{$\begin{array}{l}\text { - For Fig. } 3 \text { the alpha numerals relevant to the specific analyses are indicated in brackets after each variable } \\
\text { RSC = rank similarity cut-off; VOC = "variables of concern"; MVC = "maximum variable combination"; SQRT = square root; } \\
\mathrm{M}=\text { monthly; } \mathrm{Y}=\text { annually }\end{array}$} \\
\hline
\end{tabular}
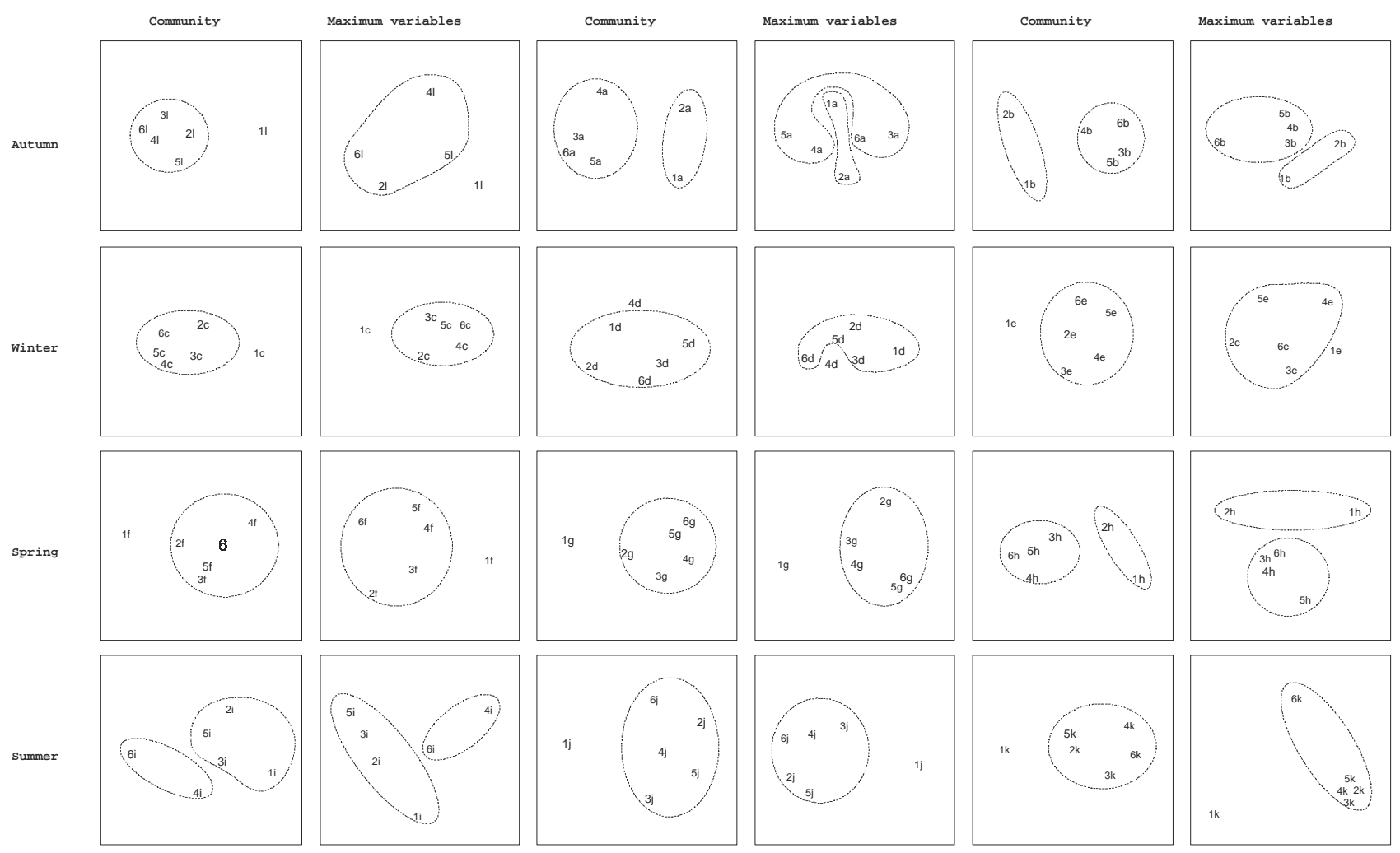

Figure 7

Monthly ordinations generated from the log-transformed "maximum variable combination" and the presence-absence-transformed family level data respectively, collected at all six sites for the duration of the study. Superimposed cluster groups were formed at a rank similarity cut-off of 10 . 
more subtle effects of stream regulation in lowland regions, which is most often due to water abstraction and weir construction (as is the case in the Mhlathuze River). It may be particularly difficult to reflect these effects with conventional biological assessment techniques such as the SASS4 rapid assessment technique (Armitage and Pardo, 1995).

- The difficulty in relating an integrated biological score to an instantaneous physical or chemical measurement has been acknowledged (Dallas, 1995).

\section{Conclusions}

Both community data and SASS4 scores were affected significantly by spatial and temporal variation in all but one instance, namely, the spatial trend in SASS4 scores after removing Site 1 from the analysis. A possible problem associated with SASS4 sensitivity ratings was reflected by the stronger temporal trend compared with the spatial trend in SASS4 scores, which was observed when Site 1 was excluded from the analysis.

The three biotic indices (SASS4, NTAXA and ASPT) were successful in reflecting patterns in macroinvertebrate community structure. HQI, however, did not succeed in accomplishing this. This possibly indicates that:

- HQI was not sensitive enough to detect the habitat changes, which affected the invertebrate community, or

- habitat quality did not play an important role in structuring the invertebrate community inhabiting the system.

The evaluation of taxonomic resolution revealed that qualitative family-level data provided an adequate classification of sites for use in routine biomonitoring. Results obtained from the study were ambiguous with respect to the importance of measuring abundance during routine biomonitoring, although many researchers have obtained results indicating that the necessary information about water quality could be provided by qualitative family level data.

When the estuarine influence was excluded, a clear environmental driving force in macroinvertebrate community structure was absent. This suggests that biological patterns in the Mhlathuze River were based chiefly on the effect of the tidal push from the Mhlathuze Estuary. No definite conclusion with respect to the ability of the SASS4 to reflect physical-chemical water quality changes could be drawn from the results obtained for the Mhlathuze River.

\section{Acknowledgements}

The authors wish to thank the Coastal Research Unit of Zululand of the University of Zululand for the use of facilities and equipment. The project was made possible through funding from the Water Research Commission and Mhlathuze Water.

\section{References}

ANONYMOUS (1983) Richards Bay/Empangeni Draft Guide Plan. Department of Constitutional Development and Planning.

ARMITAGE PD and PARDO I (1995) Impact assessment of regulation at the reach level using macroinvertebrate information from mesohabitats. Regulated Rivers: Res. Manage. 10 147-158.

ARMITAGE PD, MOSS D, WRIGHT JF and FURSE MT (1983) The performance of a new biological water quality score system based on macroinvertebrates over a wide range of unpolluted running-water sites. Water Res. 17 333-347.

CASTELLA E, BICKERTON M, ARMITAGE PD and PETTS GE (1995) The effects of water abstractions on invertebrate communities in U.K. streams. Hydrobiol. 308 167-182.

CHUTTER FM (1994) The rapid biological assessment of stream water quality by means of the macroinvertebrate community in South Africa. In: Uys MC (ed.) Classification of Rivers, and Environmental Health Indicators. Proc. of a Joint S. Afr./ Aust. Workshop, 7-14 February, 1994, Cape Town, South Africa. WRC Report No TT 63/94, Water Research Commission, Pretoria, South Africa.

CLARKE KR and WARWICK RM(1994) Change in Marine Communities: An Approach to Statistical Analysis and Interpretation. Manual for the PRIMER Statistical Package. Natural Environmental Research Council, United Kingdom.

CYRUS DP, WEPENER V, MACKAY CF, CILLIERS PM, WEERTS SP and VILJOEN A (2000) The Effects of Interbasin Transfer on the Hydrochemistry, Benthic Invertebrates and Ichthyofauna of the Mhlathuze Estuary and Lake Nsezi. WRC Report No 722/1/99.

DALLAS HF (1995) An Evaluation of SASS (South African Scoring System) as a Tool for Rapid Bioassessment of Water Quality. M.Sc. Thesis, Univ. of Cape Town, South Africa.

DALLAS HF (1997) A preliminary evaluation of aspects of SASS (South African Scoring System) for the rapid bioassessment of water in rivers with particular reference to the incorporation of SASS in a national biomonitoring programme. S. Afr. J. Aqua. Sci. 23 79-94.

DOLLAR ESJ (1998) Geomorphology. In: Louw D (ed.) Mhlathuze Ecological (Quantity) Reserve Study IFR. Unpublished starter document for IFR specialist meeting held in Mtunzini, KwaZuluNatal, South Africa, 26-30 October 1998.

FURSE MT, WRIGHT JF, ARMITAGE PD and MOSS D (1981) An appraisal of pond-net samples for biological monitoring of lotic macroinvertebrates. Water Res. 15 679-689.

GROWNS JE, CHESSMAN BC, McEVOY PK and WRIGHT IA (1995) Rapid assessment of rivers using macroinvertebrates: Case studies in the Nepean River and Blue Mountains, NSW. Aus. J. Ecol. $20130-141$.

KELBE BE and GERMISHUYSET (1999) Geohydrological Studies of the Primary Coastal Aquifer in Zululand. Draft Report to the Water Research Commission (K5/720).

MACMILLAN PH (1998) An Integrated Habitat Assessment System (IHAS v2), for the Rapid Biological Assessment of Rivers and Streams. CSIR Research Project No ENV-P-I 98132 for the Water Resources Management Programme, CSIR, Pretoria, South Africa.

MEYER R and GODFREY L (1995) Kwa-Zulu/Natal Geohydrological Mapping Project - Mapping Unit 7. CSIR Report No EMAP-C-95024, CSIR, Pretoria, South Africa.

ROUX DJ and EVERETT MJ (1994) The ecosystem approach for riverine health assessment: A South African perspective. In: Uys MC (ed.) Classification of Rivers and Environmental Health Indicators. Proceedings of a Joint South Africa/Australia Workshop. WRC Report TT 63/94, Water Research Commission, Pretoria.

ROUX DJ, KLEYNHANS CJ, THIRION C, HILL L, ENGELBRECHT JS, DEACON AR and KEMPER NP (1999) Adaptive assessment and management of riverine ecosystems: The Crocodile/Elands River case study. Water SA 25 (4) 501-511.

THORNE RJ and WILLIAMS WP (1997) The response of benthic macroinvertebrates to pollution in developing countries: A multimetric system of bioassessment. Freshwater Biol. 37 671-686.

ZAMORA-MUNOZC and ALBA-TERCEDOR JA (1996) Bioassessment of organically polluted Spanish rivers, using a biotic index and multivariate methods. J. North Am. Benth. Soc. 15 332-352. 